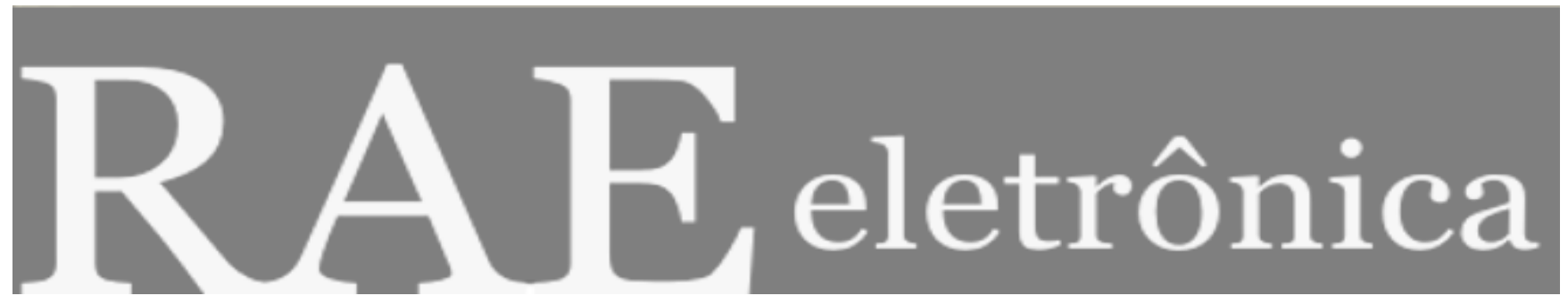

\title{
GESTÃO BASEADA EM RELAÇÕES DE CONFIANÇA
}

Por:

\section{Carolina Tiemi Sato}

RAE-eletrônica, Volume 2, Número 1, jan-jun/2003.

http://www.rae.com.br/eletronica/index.cfm?FuseAction=Artigo $\& I D=1875 \&$ Secao $=2^{\circ} \mathrm{PWC} \&$ Volume $=2 \&$ Numero $=1 \&$ Ano $=2003$

CCopyright, 2002, RAE-eletrônica. Todos os direitos, inclusive de tradução, são reservados. É permitido citar parte de artigos sem autorização prévia desde que seja identificada a fonte. A reprodução total de artigos é proibida. Os artigos só devem ser usados para uso pessoal e não-comercial. Em caso de dúvidas, consulte a redação: redacao@rae.com.br.

A RAE-eletrônica é a revista on-line da FGV-EAESP, totalmente aberta e criada com o objetivo de agilizar a veiculação de trabalhos inéditos. Lançada em janeiro de 2002, com perfil acadêmico, é dedicada a professores, pesquisadores e estudantes. Para mais informações consulte o site www.rae.com.br/eletronica.

RAE-eletrônica

ISSN 1676-5648

(C)2002 Editora: Fundação Getulio Vargas - Escola de Administração de Empresas de São Paulo.
F U N D A C Ã 0 GETULIO VARGAS

Escola de Administração de Empresas de São Paulo 


\section{$2^{\circ}$ PRÊMIO PWC - INOVAÇÃO EM GESTÃO - $1^{\circ}$ LUGAR - CATEGORIA GRADUAÇÃO GESTÃO BASEADA EM RELAÇÕES DE CONFIANÇA \\ Carolina Tiemi Sato}

\section{GESTÃO BASEADA EM RELAÇÕES DE CONFIANÇA}

\section{Carolina Tiemi Sato}

Graduanda em Administração de Empresas pela FGV-EAESP

E-mail: carolinasato@gvmail.br

Endereço: Av. Nove de Julho, 2029 - Bela Vista - São Paulo - SP, 01313-902

Interesses de pesquisa: Empreendedorismo e comportamento humano

\section{RESUMO}

O presente trabalho é um estudo de caso realizado em um hotel e seu objetivo é analisar o papel desempenhado pelas relações de confiança na gestão de uma organização e como elas são criadas no interior da organização e entre ela e seus fornecedores.

\section{Abstract}

This paper is a case study of a hotel and it aims to analyze the role played by the trust relationships in an organization, and how are they developed inside the organization and with its suppliers.

\section{Palavras-Chave}

Confiança, cooperação, gestão, turismo e hotel.

\section{KEY-WORDS}

Trust, cooperation, management, tourism and hotel. 


\section{Discussão bibliográfica}

Relações de confiança estabelecidas entre pessoas e entre empresas são processos extremamente complexos e delicados. Não por acaso, sociólogos (LUHMANN, 1996), (COLEMAN, 1990), (GAMBETTA, 1988), (SABEL, 1992), economistas (WILLIAMSON, 1985) e filósofos no campo da política (TOCQUEVILLE, 1962) e da ética (SOLOMON, 2000) vêm se debruçando sobre este tema, de modo a gerar um debate interdisciplinar bastante profícuo.

O que é confiança? DONEY, CANNON et al. (1998) chamam atenção para a variação do significado e dos tipos de confiança em diferentes culturas. Neste sentido, não há uma definição de confiança que seja universalmente aceita (ROUSSEAU, SITKIN et al., 1998). Entretanto, há vários níveis de convergência em torno do conceito. De um modo geral, os autores consideram que confiança se faz necessária em situações de risco ou incerteza, ou ainda quando interesses de um agente não podem ser alcançados sem que haja confiança de um em relação ao outro (LUHMANN, 1988). A abordagem sociológica tende a atribuir à confiança significados como lealdade, expectativas mútuas, e reciprocidade (ZUCKER, 1986).

Confiança é ainda definida como "um conjunto de expectativas compartilhadas por todos aqueles envolvidos em uma troca. HOSMER (1995) conclui que a confiança está nas expectativas de uma pessoa, grupo ou firma, baseadas em comportamentos eticamente justificáveis pelos atores sociais. Em suma, confiança pode ser vista como um conjunto de expectativas compartilhadas por pessoas, grupos ou firmas, com base na reciprocidade e boa vontade, expectativas estas, influenciadas pelo contexto institucional" (NEWELL \& SWAN, 2000, : 1293).

Os autores de um modo geral, convergem para a visão de que em um ambiente em que há confiança, o medo ou temor em agir, em realizar as atividades, em função da incerteza das conseqüências futuras, diminuem. A confiança assume um papel de extrema relevância que é o de facilitar as relações de trabalho e as trocas econômicas e, consequentemente, de fazer com que as atividades fluam melhor, que os objetivos sejam atingidos mais rapidamente e com menor custo, possibilitando, portanto, uma gestão mais efetiva. A questão da redução dos custos econômicos, gerada pelas relações de confiança é abordada especialmente pelos economistas, através de um conjunto de autores que apresentam a abordagem chamada transactional costs (WILLIAMSON, 1985).

Em termos de administração de empresas, especificamente, o tema da confiança foi introduzido muito recentemente, na área de recursos humanos. Nesse sentido, os autores irão assinalar seu papel na estrutura da organização e no processo interativo, assim como no aperfeiçoamento da competência individual. (ver: J. WHITNEY, 1993).

Embora em outros países este tema seja debatido e valorizado, no Brasil estudos sobre relações de confiança são bastante escassos. Esta pesquisa focaliza a área do turismo e lazer e se propõe a analisar como são construídas e qual é o papel desempenhado pelas relações de confiança na gestão de uma organização. Mais especificamente, nos propomos a realizar um estudo de caso em um hotel na cidade de São Paulo, onde serão investigadas as relações de confiança estabelecidas entre os funcionários desta organização e entre a organização e seus principais fornecedores. 


\section{$2^{\circ}$ PRÊMIO PWC - INOVAÇÃO EM GESTÃO - $1^{\circ}$ LUGAR - CATEGORIA GRADUAÇÃO \\ GESTÃO BASEADA EM RELAÇÕES DE CONFIANÇA \\ Carolina Tiemi Sato}

Pretendemos analisar como são desenvolvidas relações de confiança entre os funcionários de um hotel de uma mesma posição hierárquica, de diferentes cargos e posições, e também entre chefes e subordinados. Neste sentido, a principal pergunta a ser respondida pela pesquisa é como são criadas relações de confiança e qual é o papel da confiança como meio facilitador das relações de trabalho e da cooperação entre as pessoas e empresas e portanto da gestão do hotel. Quanto aos fornecedores, o objetivo é analisar como são construídas relações de confiança com o proprietário e/ou direção do hotel, qual é o papel destas relações na compra e venda de material/serviços e se estas relações reduzem os custos do hotel, melhoram a qualidade dos produtos, etc.

\section{Pesquisa de Campo}

A pesquisa de campo foi realizada no Hotel Caesar Park que pertencia originalmente ao Grupo Aoki, mas que foi vendido ao Grupo Posadas em maio de 1998.

O Caesar Park possui diversas filiais no Rio de Janeiro, Buenos Aires e São Paulo. Esta pesquisa de campo foi realizada especificamente no Hotel Caesar Park, localizado na rua Augusta, em São Paulo, no período entre fevereiro a abril de 2002.

Em linhas gerais, as entrevistas foram realizadas em quatro áreas principais: governança, recepção, alimentos e bebidas e área de compras. O organograma abaixo mostra como o hotel está estruturado em suas diferentes áreas, e permite visualizar o que esta pesquisa abrange (áreas coloridas):

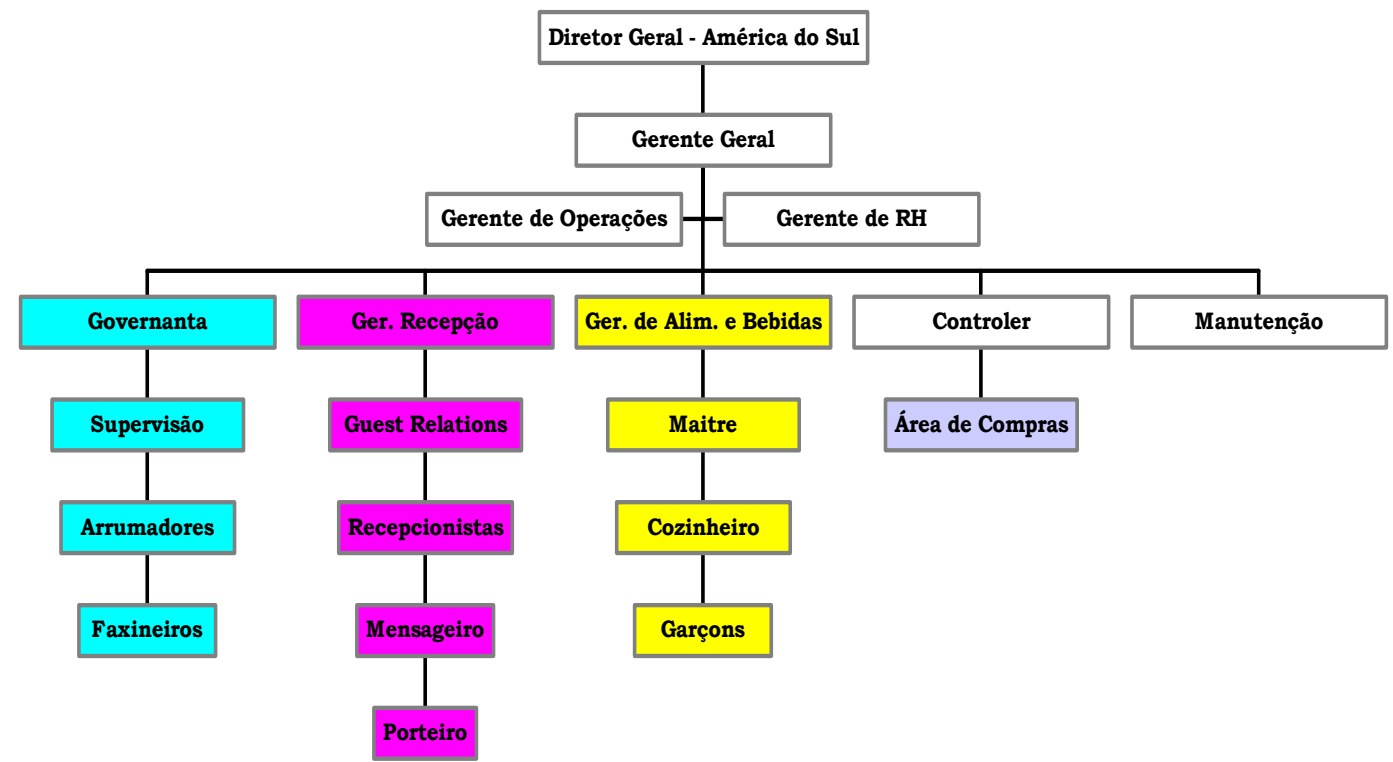

Julgamos que as áreas de governança, recepção e alimentos e bebidas são as áreas de maior relevância para a análise das relações de confiança entre os funcionários da organização porque além destas áreas realizarem as principais atividades do hotel, é nelas que trabalham a maioria dos funcionários ( $75 \%$ do total de funcionários do hotel), os quais exercem diversos tipos de atividades. Nestas áreas podemos encontrar funcionários de diversos níveis hierárquicos (como pode ser observado no organograma), ocupando diferentes cargos, o que contribuirá para a nossa investigação sobre as relações entre chefes e subordinados, além das relações entre funcionários de mesma posição 


\section{$2^{\circ}$ PRÊMIO PWC - INOVAÇÃO EM GESTÃO - $1^{\circ}$ LUGAR - CATEGORIA GRADUAÇÃO GESTÃO BASEADA EM RELAÇÕES DE CONFIANÇA \\ Carolina Tiemi Sato}

hierárquica, no intuito de detectar-se qual é o papel que a confiança exerce nestas relações que envolvem assimetria na hierarquia da organização.

A área de compras por sua vez, foi selecionada justamente para a investigação do outro objetivo que esta pesquisa estabeleceu: analisar como são construídas relações de confiança entre a organização e seus fornecedores. Esta área é responsável por todos os contatos e relacionamentos com fornecedores do hotel, todo tipo de negociação com fornecedores externos é centralizado nela.

Resumindo, as entrevistas foram realizadas nestas quatro áreas baseadas nos dois objetivos principais desta pesquisa de campo: analisar como se formam as relações de confiança entre os funcionários da organização, e entre a organização e seus fornecedores.

A tabela abaixo mostra a relação de todos os entrevistados:

\begin{tabular}{|c|c|c|c|c|c|c|c|}
\hline$\underset{1}{\text { Nome }}$ & Cargo & $\begin{array}{l}\text { Se } \\
\text { xo }\end{array}$ & $\begin{array}{l}\text { Ida } \\
\text { de }\end{array}$ & $\begin{array}{l}\text { Tempo no } \\
\text { hotel }\end{array}$ & Religião & Grau de escol. & Origem \\
\hline Ciro & Assist. de & $\mathrm{M}$ & 24 & 1 ano e meio & Católico & $3^{\circ}$ grau incompl. & Port/Espan/Af \\
\hline Luiz & $1^{\mathrm{o}}$ & $\mathrm{M}$ & 44 & 9 anos & Católico & $2^{\circ}$ grau completo & Maceió \\
\hline Arnald & $2^{0}$ & $\mathrm{M}$ & 28 & 7 anos & Católico & $2^{\circ}$ grau incompl. & Bahia \\
\hline Morae & Garcom & $\mathrm{M}$ & 28 & 4 anos & Católico & $2^{\circ}$ grau incompl. & Paraíba \\
\hline Mitiko & Ger. de & $\mathrm{F}$ & 27 & 5 anos & Budista & $3^{\circ}$ grau completo & Japoneses \\
\hline Atsuk & Guest & $\mathrm{F}$ & 39 & 4 anos & Não tem & $3^{\circ}$ grau completo & Japoneses \\
\hline João & Recepcionis & $\mathrm{M}$ & 30 & 1 ano e 1 & Crente & $3^{\circ}$ grau completo & Portugueses \\
\hline Viníci & Mensageiro & $\mathrm{M}$ & 23 & 3 anos e 6 & Católico & $2^{\circ}$ grau completo & Bahia \\
\hline Joaqui & Porteiro & $\mathrm{M}$ & 47 & 21 anos & Catól. $\tilde{n}$ & $2^{\circ}$ grau & Paraíba \\
\hline Renata & Governanta & $\mathrm{F}$ & 35 & 12 anos & Catól. ñ & $3^{\circ}$ grau completo & Bahia \\
\hline Otávio & Supervisor & $\mathrm{M}$ & 48 & 23 anos & Católico & $2^{\circ}$ grau & Minas Gerais \\
\hline Maria & Supervisora & $\mathrm{F}$ & 51 & 23 anos & Católica & Primário & Brasileiros \\
\hline Lilian & Arrumadeira & $\mathrm{F}$ & 22 & 10 meses & Catól. $\tilde{n}$ & $2^{\circ}$ gr. & Natal \\
\hline Catari & Arrumadeira & $\mathrm{F}$ & 22 & 1 ano e 1 & Paz e Vida & $2^{\circ}$ grau em curso & Bahia \\
\hline Denise & Faxineira & $\mathrm{F}$ & 28 & 10 meses & Católica & $1^{\circ}$ grau & Brasileiros \\
\hline Rome & Ger. de & $\mathrm{M}$ & 46 & 15 anoa & Católica & $2^{\circ}$ grau completo & Brasileiros \\
\hline
\end{tabular}

\section{$\underline{\text { Análise }}$}

A partir do material coletado nas entrevistas, destacamos três pontos considerados como mais relevantes para a análise:

- O que significa confiar?

- Confiança como um tipo de relação a ser construída

- O papel da confiança na relação entre organização e fornecedores

\section{- O que significa confiar?}

Podemos classificar o modo como os entrevistados definiram confiança de duas maneiras:

1) Alguns enfatizam valores; como honestidade, sinceridade e amizade para descrever uma relação em que exista confiança

\footnotetext{
${ }^{1}$ Os nomes são fictícios a fim de preservar a identidade dos entrevistados 


\section{$2^{\circ}$ PRÊMIO PWC - INOVAÇÃO EM GESTÃO - $1^{\circ}$ LUGAR - CATEGORIA GRADUAÇÃO \\ GESTÃO BASEADA EM RELAÇÕES DE CONFIANÇA \\ Carolina Tiemi Sato}

2) Outros focam-se principalmente no modo de agir das pessoas e nas expectativas que se formam dentro de uma relação.

Podemos notar isto nos trechos abaixo, retirados das entrevistas. Primeiro aqueles entrevistados que se enquadram no primeiro item, ou seja, que definem confiança a partir da percepção de valores:

A supervisora dos andares, Maria disse: "Eu acho que isso (confiança) sai sei lá uma demonstração de amizade mesmo de poder contar com a pessoa no dia-a-dia nas horas difíceis né, nas horas alegres ou nas horas tristes. Eu acho que através da amizade é que você adquire confiança nas pessoas", nesta mesma linha o supervisor de limpeza, Sr. Otávio disse: "eu tenho confiança em alguém a partir do momento que ela seja sincera, honesta”.

O porteiro da área de recepção disse: “Confiar em alguém é você acreditar naquela pessoa." - O que te leva a confiar em determinada pessoa? - "Honestidade. A sinceridade".

O Moraes, garçom, definiu confiança como: "Eu acho que confiança é respeito", e seguindo a mesma linha, o assistente de gerência da área de alimentos e bebidas, Ciro, definiu: "Confiança é respeito, honestidade".

Outros definem confiança a partir da observação de atitudes, comportamentos, e expectativas em relação às atitudes dos outros, como pode ser observado nos depoimentos abaixo:

“Confiança é uma relação muito importante. É alguém respeitar o seu agir, se por acaso não sair exatamente como a pessoa quis, ela tem que confiar no sentido de saber que você fez o melhor" Renata, governanta.

"Confiança é quando você precisa de alguém, e alguém está sempre disposto a te ensinar a te colocar pelo caminho certo, a te encorajar e vice e versa" - Lilian, camareira.

"Confiança é você poder contar para outra pessoa sobre você mesma e ela não contar para os outros" - Cristiane, camareira.

"Confiança é a pessoa acreditar que você tá ali, que você vai conseguir fazer aquilo que a pessoa espera de você." - Denise, faxineira.

"Eu acho que as pessoas que ficam comentando de outras pessoas não se deve confiar" Vinícius, mensageiro.

"Confiança é você poder acreditar na outra pessoa, sem ter que achar que a pessoa vai fazer alguma coisa errada se você não tiver presente" - Mitiko, gerente da área de recepção.

Assim, apesar de cada um dos entrevistados terem definido confiança à sua própria maneira, observa-se que as definições se classificam em um dos dois grupos: confiança definida baseando-se

em valores expressos e confiança definida baseando-se na observação de atitudes e comportamentos alheios. 


\section{$2^{\circ}$ PRÊMIO PWC - INOVAÇÃO EM GESTÃO - $1^{\circ}$ LUGAR - CATEGORIA GRADUAÇÃO \\ GESTÃO BASEADA EM RELAÇÕES DE CONFIANÇA \\ Carolina Tiemi Sato}

\section{- Confiança como um tipo de relação a ser construída}

Antes de iniciarmos nossa análise sobre como são construídas as relações de confiança dentro deste ambiente de trabalho, é importante ressaltar um fato observado durante as entrevistas. Foi constatado em algumas entrevistas que os entrevistados classificaram e distinguiram dois tipos de relação de confiança: aquela que surge em uma relação pessoal e a que se forma em uma relação profissional. Abaixo, alguns dos depoimentos:

"A gente às vezes confia na pessoa prá amizade e às vezes na pessoa do serviço, assim. Então são coisas que a gente separa." - Denise, faxineira.

“Considerando-se uma relação pessoal, nem todos no hotel são de confiança, porém para o trabalho sim." - Catarina, camareira.

"Bom, na minha equipe aqui dentro eu confio em matéria de trabalho. Em matéria de trabalho né. Tem aquelas que eu posso confiar e que não posso. Agora já confiar de uma maneira mais íntima não. Eu já diria que minha confiança seria com outras pessoas, não propriamente aqui dentro." Maria, supervisora.

Analisando-se os depoimentos observou-se dois fatores relevantes para a formação de uma relação de confiança:

1) convivência, experiências de cooperação

2) tempo

Observa-se que quando se trata do convívio profissional, do dia a dia de trabalho, as pessoas parecem ter estabelecido uma relação de confiança a partir de experiências de colaboração e até de cumplicidade durante as atividades executadas. Foi durante o convívio nas atividades cotidianas que as pessoas se conheceram e notaram quem trabalha bem, quem coopera nos momentos em que o hotel está lotado, com quem eles podem contar quando precisam de ajuda, etc.

Um exemplo de colaboração que a camareira Lilian citou: "Você espera a semana inteira por um dia de folga, aí de repente alguém pede, o hotel está lotado, alguém pede que você troca a folga e você troca na maior. Você tá precisando de alguém que entre mais cedo, é só falar e a pessoa não mede esforços para entrar mais cedo"(sic). A faxineira Denise, por outro lado, citou um exemplo de não colaboração: "o hotel tava lotado então eu precisei, tava correndo, agitada nos banheiros, limpando e um colega de serviço que tava sem fazer nada queria que eu fosse fazer o serviço dele, que era limpar os cinzeiros. Aí então ele ligou para a governanta e falou que era pra mim limpar, só que eu tava ocupada então eu achei assim, que foi uma falta de colaboração da parte dele, entendeu”(sic).

O Moraes, garçom na área de alimentos e bebidas também citou um exemplo de colaboração que ele percebe no dia a dia de seu trabalho: "como hoje a gente tá preocupado, então a gente coloca o caixa na frente, ele fica recepcionando, o cozinheiro que percebe que a gente tá com movimento a gente pede pro prato sair um pouco mais rápido ou com uma qualificação diferente que tá no cardápio, ele faz sem reclamar, então esse é um exemplo do que eles colaboram”(sic). 


\section{$2^{\circ}$ PRÊMIO PWC - INOVAÇÃO EM GESTÃO - $1^{\circ}$ LUGAR - CATEGORIA GRADUAÇÃO \\ GESTÃO BASEADA EM RELAÇÕES DE CONFIANÇA \\ Carolina Tiemi Sato}

Já o Ciro, assistente de gerência desta mesma área também citou um exemplo de colaboração, porém desta vez em relação às outra áreas: "eu vejo por exemplo o pessoal da governança que quando vem aqui no restaurante quando eles precisam aspirar, para limpar o restaurante, os próprios garçons ajudam, apoiam, afastam as mesas para que a limpeza seja feita de uma forma melhor, o pessoal da governança quando vê que tem alguma xícara suja no lobby, pires, cinzeiro, mesa suja, cadeira mal posicionada, eles também tomam o cuidado de nos alertar neste sentido, quando a ocupação está muito alta e há necessidade de entregar 10, 15 bebidas no quarto ao mesmo tempo os mensageiros vêm ajudar, a gente se precisar a gente ajuda o pessoal da recepção a subir as malas para os apartamentos quando tem muito check in ao mesmo tempo. Eu mesmo entro na cozinha para cozinhar, eu venho de vez em quando para carregar bandeja, vou para o balcão da recepção para fazer o check in e assim por diante".

Observa-se que as pessoas percebem a presença de colaboração por parte de seus colegas nos gestos mais simples e corriqueiros, nas atividades rotineiras e durante a convivência diária com os demais funcionários. E com o passar do tempo uma relação de confiança vai se estabelecendo, como podemos observar no comentário do chefe de cozinha, Arnaldo: "O Silveira representa prá gente a cozinha, mas ele pode falar assim, 'gente eu tô indo embora tá, eu vou lá amanhã a gente se vê'. Ele deixou prá gente uma confiança de que a gente vai tá fazendo o papel correto, sem nenhuma dificuldade, e outra ele não vai tá cobrando do Zé (ajudante de cozinha), ele não cobra isso porque ele sabe que é o Zé”.

Nota-se que após uma etapa de conhecimento mútuo, as pessoas passam a identificar nas pessoas fatores que os fazem confiar ou não. Isso fica mais claro no exemplo que a Maria, supervisora de governança nos deu: "nós temos um arrumador que ele é meio enrolão...eu passo as tarefas, mas não posso acompanhar ali, 12 horas por dia, 24 horas por dia. Se eu passo a tarefa, vou fazer o meu trabalho ciente de que ele esteja fazendo o dele. Só que muitas vezes quando eu volto, o serviço não está completo ou está deixando a desejar, então a gente tem que tá sempre, são o tipo de pessoa que você tem que trabalhar mais próximo delas né". Quando perguntado se ela confia neste funcionário: "Não. Não confio".

Desta maneira, percebemos que cada funcionário forma sua opinião sobre os demais através da convivência, da troca de favores, de gestos de colaboração durante as atividades do dia a dia e gradativamente a confiança vai se estabelecendo entre a equipe. Assim, ao longo do tempo as pessoas foram se adaptando ao ambiente de trabalho, à forma de se trabalhar, e à equipe. Aliás, independentemente do tipo de relação estabelecida (profissional ou pessoal, de amizade), o fator tempo foi citado por todos como essencial para se desenvolver uma relação de confiança. Abaixo alguns exemplos:

"Na época as pessoas torceram o nariz porque entrei, eu tenho certeza de que se eu sair hoje, vai acontecer exatamente o contrário, as pessoas confiam na minha pessoa" - Renata, governanta.

“Olha a primeira vez que eu entrei aqui há 23 anos atrás eu tive um pouco de dificuldade porque eram aquelas pessoas que achava 'Ah, tá entrando uma arrumadeira nova, ela vai me substituir'...com o passar do tempo elas viram que eu apenas tentei mostrar o meu trabalho"(sic) - Maria, supervisora.

"Eu acho que você adquire confiança com o tempo, conhecendo a pessoa" - Vinícius, mensageiro. 
Assim, os dois fatores que mostraram-se mais relevantes na formação de uma relação de confiança entre os funcionários do hotel foram: convivência, experiências de cooperação e tempo.

\section{- O papel da confiança na relação entre organização e fornecedores}

A área de compras é a responsável em negociar e lidar com todos os fornecedores do hotel, independentemente do tipo de produto ou serviço que o hotel irá adquirir.

As necessidades de compra são definidas em cada área (recepção, governança, alimentos e bebidas e demais áreas administrativas) e reportadas à área de compras. A partir deste momento, cabe à área de compras pesquisar o que será comprado, avaliar o orçamento e comprar o que foi pedido.

Surpreendentemente, apesar do tamanho do hotel, e da grande demanda de compras que ele necessita para o seu dia a dia, a área de compras é gerenciada por uma única pessoa, o supervisor de compras. É ele quem cuida de todas as negociações com os fornecedores externos, e atua como fornecedor interno do hotel.

O Sr. Romeu trabalha há quinze anos no Caesar Park entrou como motorista, foi promovido para atuar como auxiliar dentro do hotel, e depois como assistente, até chegar ao cargo de supervisor da área de compras.

O hotel possui inúmeros fornecedores, em média, existem de três a quatro fornecedores para cada item de produtos (é importante ressaltar, que foi após o grupo Posadas ter assumido o hotel que tornou-se regra fazer no mínimo três cotações para cada item de produto).

Antes mesmo de perguntarmos sobre o papel da confiança no relacionamento entre o hotel e os seus fornecedores, ele já citou o fator confiança quando respondia sobre a existência de fornecedores antigos no hotel:

"Nós temos vários fornecedores que já estão aí com nós há dez, doze anos. São fornecedores bons, aqueles que você pode confiar. Você sabe que o produto deles não vai dar, não vai trazer problemas pra nós. O preço é sempre uma coisa fixa, não aquele negócio de toda semana sobe e desce. Entendeu? Quando eles entregam determinado produto, você sabe que não vai tá faltando. Que a qualidade não vai tá inferior. Então nós temos ainda alguns fornecedores nesse estilo. Ainda mantemos os mesmos"(sic).

Ele citou como exemplo a empresa Vigor que trabalha como fornecedora do hotel há quase vinte e dois anos, assim como também a Paulista e a Agrofrutas.

Uma observação muito relevante que ele explicou foi a de que cada vez mais a relação comprador-fornecedor se modifica. Já não é mais correta a crença de que o fornecedor deve fazer todas as concessões e o comprador só faz exigências. Pelo contrário, cada vez mais, torna-se muito importante estabelecer uma relação duradoura, de parceria para que exista uma colaboração mútua, principalmente nos momentos de urgência (necessidade de entrega imediata, por exemplo). Além disso, quando já existe uma relação estabelecida, constatou-se que a própria negociação de preços, prazos e formas de pagamento torna-se mais fácil. Nas palavras do supervisor de compras: 


\section{$2^{\circ}$ PRÊMIO PWC - INOVAÇÃO EM GESTÃO - $1^{\circ}$ LUGAR - CATEGORIA GRADUAÇÃO \\ GESTÃO BASEADA EM RELAÇÕES DE CONFIANÇA \\ Carolina Tiemi Sato}

"Hoje nós temos que trabalhar no sistema de parceria. Então você numa parceria, com um tratamento bom com eles, você consegue tudo. Você consegue desconto, você consegue prolongamento de pagamento, você consegue que eles te entreguem produtos até parceladamente prá que você também não tenha que pagar tudo de uma vez. Prá que você não tenha que fazer estoque. Eles passam a ser parceiros e um amigo. Você precisa de um material em cima da hora, correndo, prá ontem, como a gente fala, eles vêm te arrumar isso, eles vêm te trazer"(sic).

Quando questionado sobre o que é confiança, o Sr. Romeu respondeu: "Confiança no meu ponto de vista é aquilo, é o tipo daquela famosa cumplicidade. Você me fala determinada coisa, você me explica determinada situação e eu passo a acreditar nisso que você tá me falando, porque eu tô vendo que você tá sendo sincero, tá sendo, tá falando, tá procurando falar a verdade, não está mentindo, não tá tendo que mentir, inventando uma desculpa para determinadas ocasiões."

E percebe-se que a relação de confiança com os fornecedores também se estabelece com o passar do tempo, após um período de convivência. Podemos observar isso no comentário do Sr. Romeu abaixo:

"O fornecedor vai te entregar, é como eu te falei. Ele passa a te fornecer hoje. Tô confiando no produto dele. Ele me mandou amostra desse produto, eu já examinei esse produto. Ele tá me entregando, a $1^{\mathrm{a}}$ quinzena, o $1^{\mathrm{o}}$ mês, o $2^{\mathrm{o}}$ mês, o $3^{\mathrm{o}}$ mês, e eu nesse tempo vou estar tendo um relacionamento com ele, vou estar conversando com ele sempre, vou estar querendo saber coisas sobre a empresa dele, coisas sobre os clientes deles, coisas sobre os fornecedores dele. Eles também têm fornecedor...aí sim eu tô vendo se ele tá sendo sincero comigo, ou ele não tá sendo sincero comigo, ou ele tá fazendo pressão prá poder vender".

A relação entre a organização e seus fornecedores é delicada no sentido de que a parceria é informal, não há contratos, nem documentação, como o próprio Sr. Romeu explicou: "Ela (parceria) não é uma coisa formal que você tem que fazer uma documentação, não precisa nada disso. Hoje basta mais o jeito de falar com eles. A maior parte desses fornecedores antigos é isso. E os novos eles já tão entrando também com a mesma filosofia. Quando eles vêm prá cá prá tentar implantar o produto deles aqui dentro que foi aceito, na hora nós já conversamos, já explicamos quais as rotinas, quais as normas, quais os horários que nós temos que ter desse material, quantidades que temos desses materiais aqui dentro".

No entanto, observamos que é muito válido conseguir formar parcerias duradouras, e estabelecer uma relação de confiança ao longo do tempo com os fornecedores, pois isso garante ao hotel vantagens nas negociações de prazos, formas de pagamento, como já citado anteriormente, além de facilitar o próprio trabalho da área de compras, pois ambas as partes já sabem como proceder com suas obrigações.

\section{Conclusão}

Este estudo de caso teve como objetivo analisar o papel desempenhado pelas relações de confiança na gestão de uma organização e como elas são criadas em seu interior e com seus fornecedores.

Vários autores, entre eles COLEMAN (1990), AXELROD (1984) e GAMBETTA (1988) convergem para a idéia de que relações de confiança demandam tempo para serem construídas, neste 


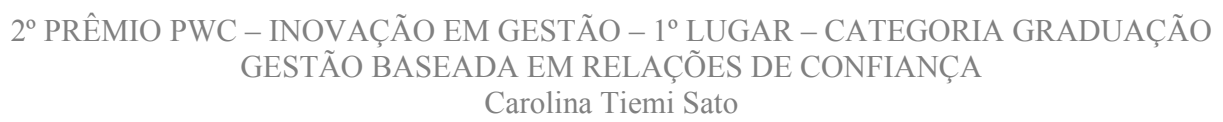

sentido, este estudo também constatou a partir dos resultados obtidos, que a relação de confiança tanto entre os funcionários da organização, como entre a organização e seus fornecedores foi construída com o passar do tempo, através da convivência e do compartilhamento de experiências. A confiança se formou principalmente a partir de atitudes de cooperação entre os envolvidos ao longo do tempo. Pudemos verificar nos depoimentos dos entrevistados que foi a partir de gestos de ajuda e cumplicidade que eles perceberam quem são as pessoas com as quais eles podem confiar. Ou seja, pode-se dizer que foi a partir da convivência que as pessoas obtiveram informações umas das outras e puderam decidir quem são aquelas pessoas com as quais elas dividiriam uma relação de confiança.

Em relação aos fornecedores, a confiança pode ser observada através da existência de um contrato informal entre as partes.

Como constatado, o hotel cada vez mais, tenta trabalhar em parceria com seus fornecedores, buscando estabelecer uma relação duradoura. Por exemplo, hoje o hotel possui empresas que lhe fornecem produtos há 22 anos, como é o caso da Vigor, Paulista e Agrofrutas. A relação entre as partes é principalmente baseada na confiança e na convivência ao longo dos anos. Como nos foi explicado pelo gerente de compras, nas negociações com fornecedores antigos: "Nós temos vários fornecedores que já estão aí com nós há 10 anos, 12 anos. São fornecedores bons, aqueles que você pode confiar. Você sabe que o produto deles não vai dar, não vai trazer problemas para nós. O preço é sempre uma coisa fixa, não aquele negócio de toda semana sobe desce...quando eles entregam determinado produto, você sabe que não vai tá faltando. Que a qualidade não vai tá inferior".

Além disso, constatou-se que a existência de confiança na relação entre organização e fornecedores reduz os custos na medida que se permite ao hotel obter vantagens como: flexibilidade para definição de prazos de entrega, facilidade no pagamento, atendimento exclusivo aos pedidos de mercadorias, descontos, etc.

Também em relação à definição de confiança, este estudo constatou duas maneiras que os funcionários do hotel utilizam para definir confiança:

1) Alguns declaram ter predisposição para confiar na pessoa em que eles identificam valores como honestidade, sinceridade e amizade.

2) Outros focam-se principalmente no modo de agir das pessoas, são mais precavidos no sentido de que a confiança surge após um tempo de convivência, de experiências de cooperação baseadas nas expectativas que se formam dentro de uma relação.

Desta forma, a confiança é definida basicamente através de dois pontos de vista, um que enfatiza o discurso, ou seja, fundamenta-se em valores que são intrínsecos à pessoa e outro que enfatiza um lado prático, que requer experiências e convivências entre as partes. Neste caso, a confiança surge justamente quando a partir do confronto entre as expectativas e a prática nota-se que há uma concordância. Ou seja, a ação ou atitude de uma parte atingiu as expectativas da outra.

GAMBETTA (1988) cita em seus estudos que o compartilhamento de crenças, valores culturais ou morais levam à cooperação entre as partes. E esta foi uma das maneiras que os funcionários expressaram suas percepções de confiança. Nota-se que confiança e cooperação estão intimamente relacionados na medida que constata-se, como já mencionado, que a confiança é percebida através de atos de cooperação ao longo do tempo. 
GAMBETTA (1988) afirma ainda que confiança não é pré-condição para que exista cooperação, e sim é resultado dela, pois baseada em experiências anteriores de cooperação é que a confiança vai sendo construída e fortalecida e como vimos, isto foi constatado em algumas entrevistas deste estudo de caso. Por outro lado, é importante frisar que parte dos entrevistados demonstraram ter uma predisposição a confiar nas pessoas, sem necessariamente ter vivenciado algum tipo de experiência anterior que tenha envolvido cooperação entre eles. Observou-se que estas pessoas que têm esta predisposição a confiar, a têm com aquelas pessoas nas quais elas identificam certos valores como honestidade e sinceridade.

Mas, podemos dizer, independentemente da forma como a relação de confiança foi formada, que a existência de confiança entre os funcionários resulta em cooperação, e desta forma agiliza e facilita as tarefas e o desempenho geral da organização e mostra que a confiança funciona como um meio facilitador das atividades diárias dos funcionários do hotel e portanto, facilita a gestão da organização como um todo. Além disso, constatou-se que a existência de confiança na relação entre organização e fornecedores reduz custos na medida que se permite ao hotel obter vantagens como: flexibilidade para definição de prazos de entrega, facilidade no pagamento, atendimento exclusivo aos pedidos de mercadorias e descontos.

\section{BIBLIOGRAFIA}

\section{Livros:}

AXELROD, Robert. The evolution of Cooperation. New York : Basic Books, 1984.

BARRETTO, Margarita. Manual de Iniciação ao Estudo do Turismo. Campinas : Papirus Editora, 1999.

BERVIAN, P.A., CERVO, A.L. Metodologia Científica. São Paulo: McGraw-Hill, 1983.

BRANDENBURGER, Adam M, NALEBUFF, Barry J. Co-opetition. 2.ed. New York : Currency Doubleday, 1996.

COLEMAN, James. Foundations of Social Theory. Cambridge : Harvard Press, 1990.

COUTINHO, Luciano, FERRAZ, João Castro. Estudo sobre a competitividade das indústrias brasileiras. Editora Papirus, MCI/UNICAMP, 1995.

DASGUPTA, Partha. Trust as a Commodity. In: GAMBETTA, Diego. Trust : Making and Breaking Cooperative Relations. Editora Basil Blackwell, 1988.

FUKUYAMA, Francis. The Great Disruption. New York : Simon \& Schuster, 2000.

FUKUYAMA, Francis. Trust : The social virtues and the creation of prosperity. New York : Free Press, 1995. 


\section{$2^{\circ}$ PRÊMIO PWC - INOVAÇÃO EM GESTÃO - $1^{\circ}$ LUGAR - CATEGORIA GRADUAÇÃO \\ GESTÃO BASEADA EM RELAÇÕES DE CONFIANÇA \\ Carolina Tiemi Sato}

GAMBETTA, Diego. Trust : Making and Breaking Cooperative Relations. Editora Basil Blackwell, 1988.

LUHMANN, Niklas.Confianza. Editora Anthropos, 1996

MACEDO, Ronaldo. Contratos Relacionais e Defesa do Consumidor. São Paulo : Max Limonad, 1998.

MARSHALL, Edward M. Transforming the way we work: The Power of the Collaborative workplace. New York : Amacom, 1995.

PAIVA, Maria das Graças de Menezes V. Sociologia do Turismo. Campinas : Papirus Editora, 1995.

PUTNAM, Robert. Bowling Alone. New York : Simon \& Schuster, 2000.

ROESCH, Sylvia M. A. Projetos de Estágio e de Pesquisa em Administração. São Paulo: Atlas, 1999.

SABEL, Charles. Studied trust : Building new forms of cooperation in a volatile economy in Industrial districts and local economic regeneration. Geveva : International Institute for Labour Studies, 1992.

SALAH, Eldin Abdel Wahab. Introdução à administração do Turismo. São Paulo : Biblioteca Pioneira de Administração e Negócios, 1977.

SOLOMON, Robert C. A melhor Maneira de Fazer Negócios: Como a integridade pessoal leva ao sucesso corporativo. São Paulo: Negócios Editora, 2000.

TOCQUEVILLE, Alexis. A democracia na America. Belo Horizonte: Itaiaia, 1962.

ZUCKER, L. G. Production of trust: Institutional sources of economic structure, 1840-1920. In:

STAW, B., CUMMINGS, L. L. Research in Organizational Behavior. Greenwich: JAI Press, 1986, 8, $53-111$

WHITNEY, John. The Economics of Trust : Liberating profits \& restoring corporate vitality. New York : Mac Graw-hill, 1993.

WILLIAMSON, O. E. The Economic Institutions of Capitalism. New York : Free Press, 1985. YIN, R. Case study research: design and methods. Londres: Sage, 1994.

\section{Artigos, Teses e Publicações :}

BACHMANN, Reinhard. Trust, Power and Control in Trans-Organizational Relations. Organization Studies, The Netherlands, n.22, p. 337-365, 2001.

DAS, T. K., TENG, Bing-Sheng. Organization, Trust, Control, and Risk in Strategic Alliances: An Integrated Framework. Organization Studies, The Netherlands, n.22, p. 251-283, 2001. 
DONEY, Patricia M., CANNON, Joseph P., MULLEN, Michael. Understanding the Influence of National Culture on the Development of Trust. Academy of Management Review, 601-620, 1998.

GREY, Chris, GARSTEN, Christina. Organization, Trust, Control and Post-Burocracy. Organization Studies, The Netherlands, n.22, p. 229-249, 2001.

JACOMINO, Dalen. Você é um Profissional Ético?. Você.s.a., (25), 28-37, 2000.

LEVERING, Robert. Confiança e Cooperação : O lucro gerado por um excelente local para se trabalhar. RAE light, 2(4), 14-20, 1995.

MAGUIRE, Steve, PHILLIPS, Nelson, HARDY, Cynthia. When 'Silence = Death', Keep Talking: Trust, Control and the Discursive Contruction of Identity in the Canadian HIV/AIDS Treatment Domain. Organization Studies, The Netherlands, n.22, p. 285-336, 2001.

NEWELL, S., SWAN, J. Trust and inter-organizational networking. Human Relations. 53, 10, 1287 $1328,2000$.

REED, Michael I. Organization, Trust and Control: A Realist Analysis. Organization Studies, The Netherlands, n.22, p. 201-227, 2001.

SERSON, Fernando Mindlin. Pontos de Excelência e de Fracasso nos Serviços : Uma reflexão acerca da teoria e implicações práticas nos serviços básicos de hotelaria. São Paulo : FGV/Escola de Administração de Empresas de São Paulo, 1998. 115p. (Dissertação, Mestrado, Mercadologia)

SITKIN, Sim B., ROUSSEAU, Denise M., BURT, Ronald S., CAMERER, Colin. Special Topic Forum on Trust in and Between Organizations. The Academy of Management Review - Special Issue Editors. 23, 3, 1998. 